\title{
Brain network dysfunctions in addiction: a meta-analysis of resting-state functional connectivity
}

\author{
Serenella Tolomeo ${ }^{1 凶}$ and Rongjun Yu (iD ${ }^{2,3,4}$ \\ (c) The Author(s) 2022
}

Resting-state functional connectivity (rsFC) provides novel insights into variabilities in neural networks associated with the use of addictive drugs or with addictive behavioral repertoire. However, given the broad mix of inconsistent findings across studies, identifying specific consistent patterns of network abnormalities is warranted. Here we aimed at integrating rsFC abnormalities and systematically searching for large-scale functional brain networks in substance use disorder (SUD) and behavioral addictions (BA), through a coordinate-based meta-analysis of seed-based rsFC studies. A total of fifty-two studies are eligible in the meta-analysis, including 1911 SUD and BA patients and 1580 healthy controls. In addition, we performed multilevel kernel density analysis (MKDA) for the brain regions reliably involved in hyperconnectivity and hypoconnectivity in SUD and BA. Data from fifty-two studies showed that SUD was associated with putamen, caudate and middle frontal gyrus hyperconnectivity relative to healthy controls. Eight BA studies showed hyperconnectivity clusters within the putamen and medio-temporal lobe relative to healthy controls. Altered connectivity in salience or emotion-processing areas may be related to dysregulated affective and cognitive control-related networks, such as deficits in regulating elevated sensitivity to drug-related stimuli. These findings confirm that SUD and BA might be characterized by dysfunctions in specific brain networks, particularly those implicated in the core cognitive and affective functions. These findings might provide insight into the development of neural mechanistic biomarkers for SUD and BA.

Translational Psychiatry (2022)12:41; https://doi.org/10.1038/s41398-022-01792-6

\section{INTRODUCTION}

Substance use disorder is characterized by excessive drug-seeking and taking [1]. Its core clinical symptoms comprise a chronically relapsing cycle of binging, intoxication, withdrawal and craving, despite the enormous adverse consequences. Behavioral addictions (BA) or non-substance addictions, such as gambling addiction, are defined as a set of behavior that the individual becomes dependent on. Both disorders are characterized by a persistent compulsion to seek and take a drug or perform a behavior, loss of control in limiting the intake, and they are often accompanied by negative emotions when the availability of the drug or behavior is prevented [2].

Both SUD and BA are complex multifaceted and multistage diseases. A previous rsfMRI systematic review reported that addictions would engage a range of brain networks, including the reward network, executive network and the habit and memory networks [3], and are broadly linked with changes in many cortical and subcortical brain regions. Among these addiction-related networks, it is crucial to identify key brain regions/networks that specifically contribute to addiction, in order to shed light on prevention and treatment. To assess the neural correlates of addictions, a number of functional neuroimaging studies have examined abnormalities in local brain regions and in communication between functionally distinct brain regions, as reported in two recent meta-analyses $[4,5]$. These studies primarily used task-based functional magnetic resonance imaging (fMRI) to assess aberrant recruitment of brain regions in the context of different experimental paradigms and stages of addiction [6-9].

As an alternative approach to task-based fMRI, resting-state (rs) fMRI has been widely applied in both healthy participants and patients with neurological and psychiatric disorders [10-12]. Rs-fMRI is based on fluctuations of the blood-oxygenation-leveldependent (BOLD) signal, which characterize the intrinsic neuronal activity of the brain while subjects are in the awake state [13]. The literature evaluating rs-fMRI in substance and nosubstance addiction is quite broad and includes seed-based functional connectivity (FC), regional homogeneity (ReHo), independent component analysis (ICA), amplitude of lowfrequency oscillations (ALFF) and graph analysis under different types of addictions (for review see: Fedota and Stein, 2015; leong and Yuan, 2017, Pariyadath et al., 2016; Sutherland et al., 2012) [14-17].

Previously, Tahmasian and colleagues concluded that seedbased FC and effective connectivity are the standard methods to detect disruption of specific brain areas, whereas graph- and network-based analyses are valuable methods for assessing alterations across the whole brain networks [12]. These different methodological approaches have provided quite an ambiguous overview of the pathophysiological mechanisms underlying SUD and BA. For this reason, reviewing the literature, together with a

\footnotetext{
${ }^{1}$ Institute of High Performance Computing, Agency for Science, Technology and Research (A*STAR), Singapore, Singapore. ${ }^{2}$ Department of Management, Hong Kong Baptist

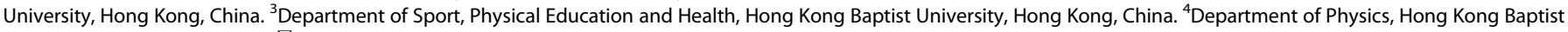
University, Hong Kong, China. ${ }^{凶}$ email: Serenella_Tolomeo@ihpc.a-star.edu.sg; rongjunyu@hkbu.edu.hk
}

Received: 16 June 2021 Revised: 5 January 2022 Accepted: 12 January 2022

Published online: 28 January 2022 


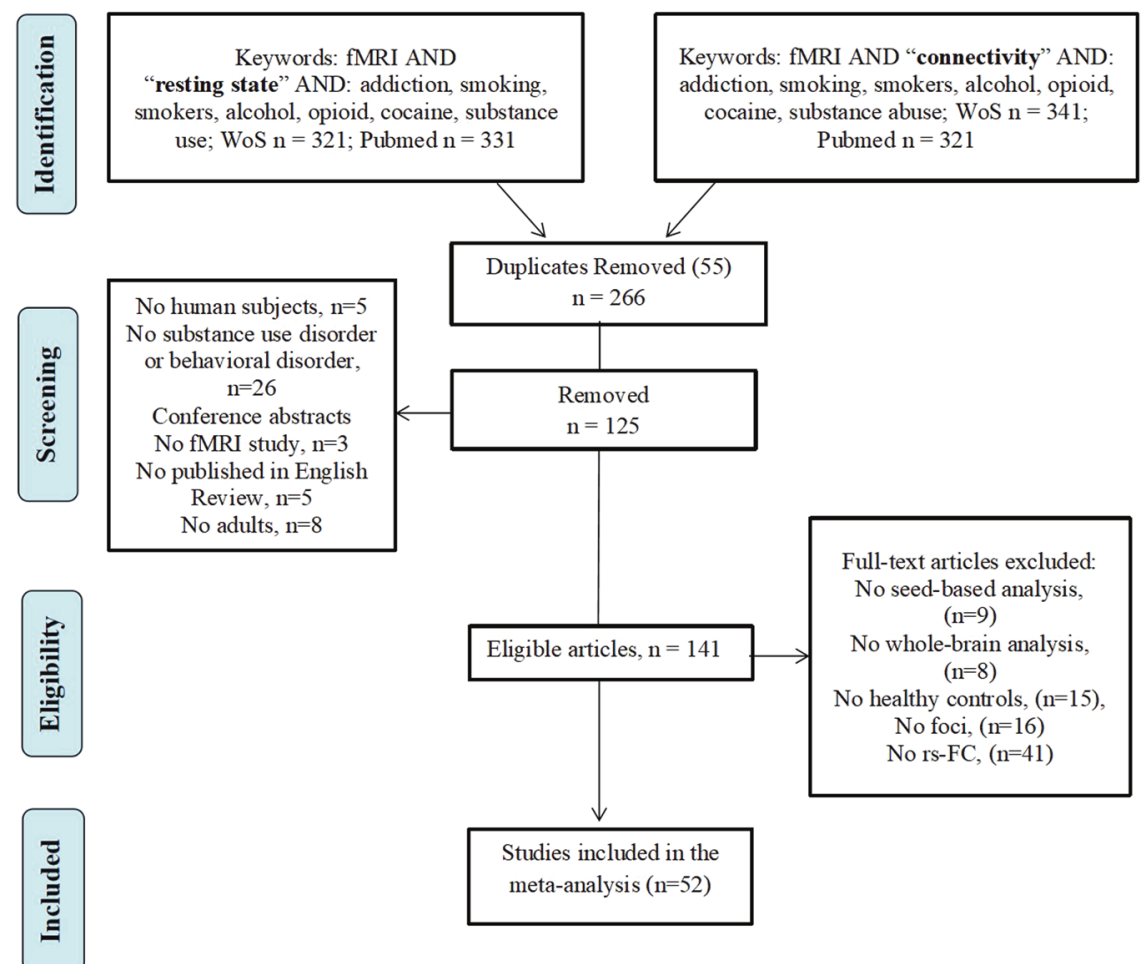

Fig. 1 PRISMA flowchart. PRISMA flowchart for the selection of eligible studies.

quantitative meta-analysis, is needed to explain the inconsistencies between previously published works.

SUD and BA might have common disease aetiologies [18, 19]. It is important to highlight the similarities and differences between these two types of addictions. For example, similar to drug addiction $[20,21]$ a number of studies concluded that pathological gambling is characterized by white matter abnormalities [22-24] and reductions of cortical thickness [25]. However, one study reported increased corticolimbic connectivity in cocaine dependence, and a decrease in pathological gambling [19], suggesting that SUD and BA may also be associated with distinct brain abnormalities.

To the best of our knowledge, no previous rsFC studies have directly compared SUD and BA to probe for neural specificity. Individuals in general show unique patterns of addiction. Although a small proportion of addicts show addiction cooccurrence, many addicts struggle with one or more addictive behaviors but do not have difficulty with other types of addictive behaviors. For example, gambling addiction is only weakly associated with drug abuse. Addiction specificity describes this phenomenon: one addictive pattern may be acquired whereas another is not [26]. To date, the neurobiological evidence on why some addictions may not co-occur within the same individual has not been conclusively quantified. Similarly, the neural basis of cooccurrence of addictions remain elusive as well [27]. We believe that it is important to directly compare the neural substrates of various types of addiction and examine the neural specificity of each addiction. Such an approach may help explain addiction specificity and addiction co-occurence.

Here we conducted two coordinate-based meta-analysis approaches activation likelihood estimation (ALE) and Multilevel Kernel Density Analysis (MKDA). Both ALE and MKDA are coordinate-based meta-analysis (CBMA) approaches. Specifically, the ALE method involves the modeling of the reported loci of maximum activation as peaks of a 3D Gaussian probability, which is defined by a specified full-width half-maximum (FWHM). 3D
Gaussian distribution produces a statistical map that assesses the likelihood of activation for each voxel as determined by all studies in the analysis [28]. Instead, the MKDA method establishes a binary map for each study, which are averaged giving the proportion of studies with any foci within a given radius from a voxel [29]. ALE focuses on the distribution of peak coordinates [28], while MKDA focuses on the distribution of statistical contrast maps [29]. We conducted a systematic review and three ALE metaanalyses of resting-state functional connectivity ( $r s F C$ ) studies. Both hypo and hyper connectivities were examined delineate the abnormality patterns among intrinsic functional networks in substance use disorders and behavioral addictions. Finally, using the Multilevel Kerned Density Analysis (MKDA) meta-analytic technique, we aimed to replicate the findings of our first metaanalyses employed using a different meta-analytic technique [28].

\section{METHODS}

\section{Search strategy}

A comprehensive literature search was carried out using Pubmed (https:// www.ncbi.nlm.nih.gov/pubmed/) and Web of Science (http://www. webofknowledge.com) in August 2021. This was performed by combining a total of 18 searches using the key terms: ["rest" OR "resting"] and ["connect" OR "connectivity"], ["fMRI" OR "neuroimaging"] and various key terms corresponding to each search: "addiction", "substance use disorder", "substance abuse", "alcohol", "cocaine", "opioid", "smokers", "smoking", "heroin", "stimulants", "methamphetamine", "gambling", "gaming" and "internet gaming". The search resulted in 139 papers and after screening seventy-two papers were reached. Figure 1 displays a PRISMA diagram of the specific search method reported. Notably, most resting-state connectivity meta-analysis analyses are based on these seventy-two studies, see Table 1 for further details.

We included original functional magnetic resonance imaging (fMRI) studies that used seed-based rsFC:

1. To compare group differences in seed-based functional connectivity among SUD-HC were examined using the results of between-group contrasts (SUD $<\mathrm{HC}$ and SUD $>\mathrm{HC}$ ). 


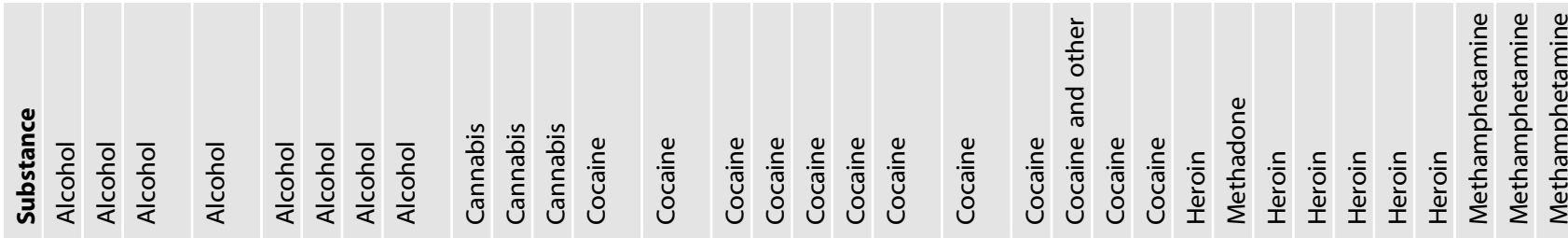

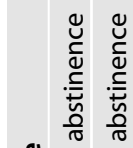

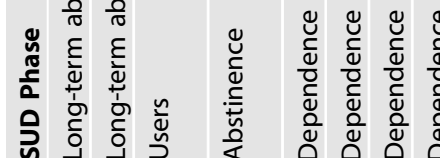
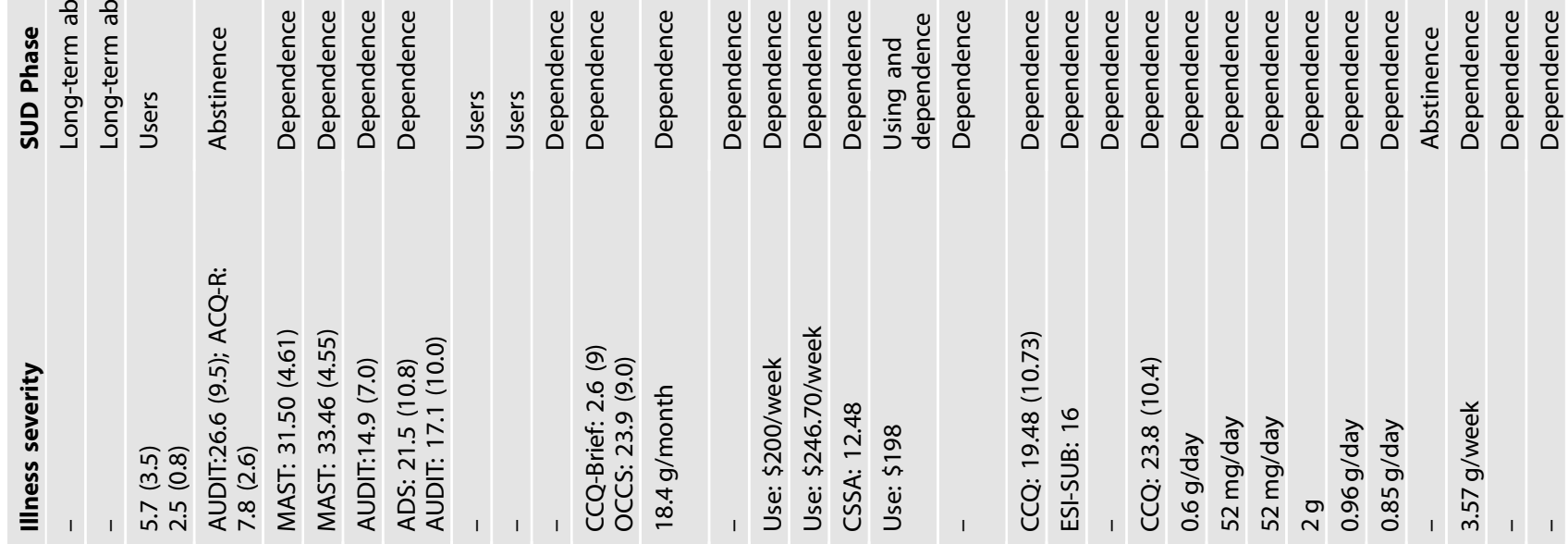

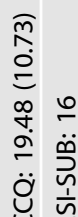

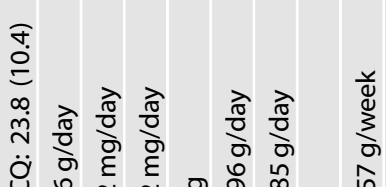

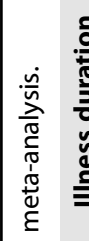
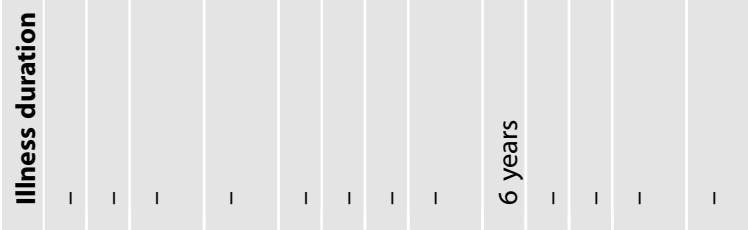

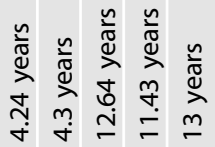

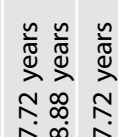

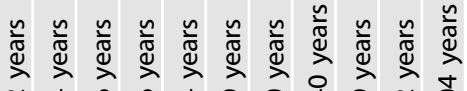

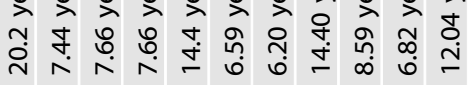

足

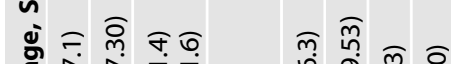

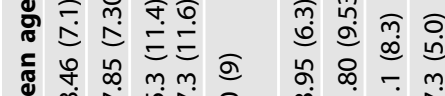

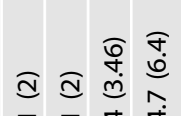

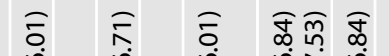

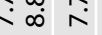

$\bar{n} \overline{4} \dot{d}$

它

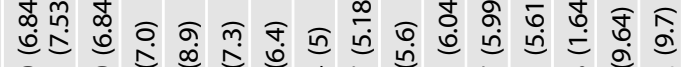

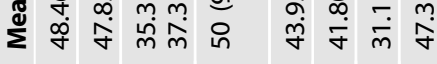

ơ

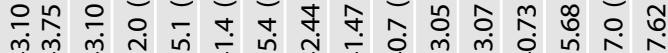

巨

綧

$\breve{x}$

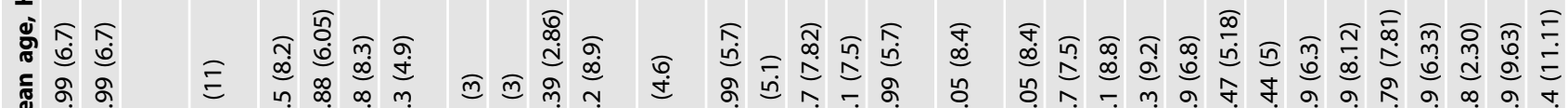

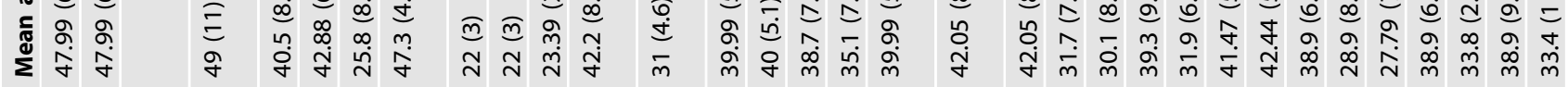

$\widehat{\Xi}$

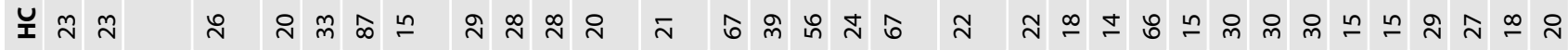

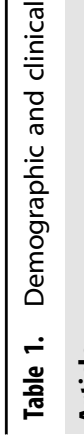

留突

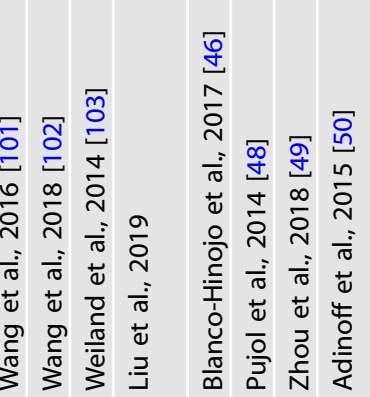

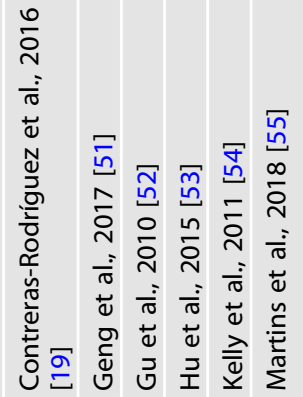

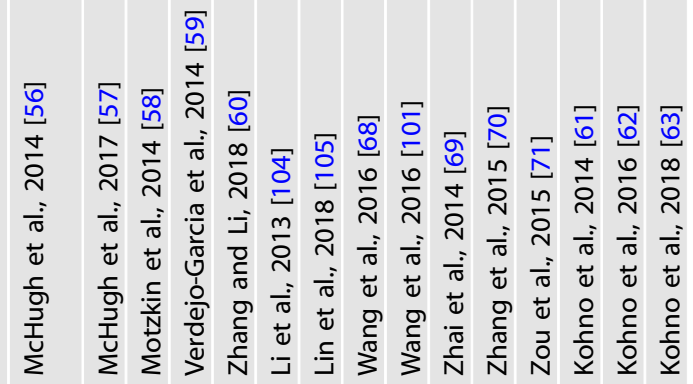



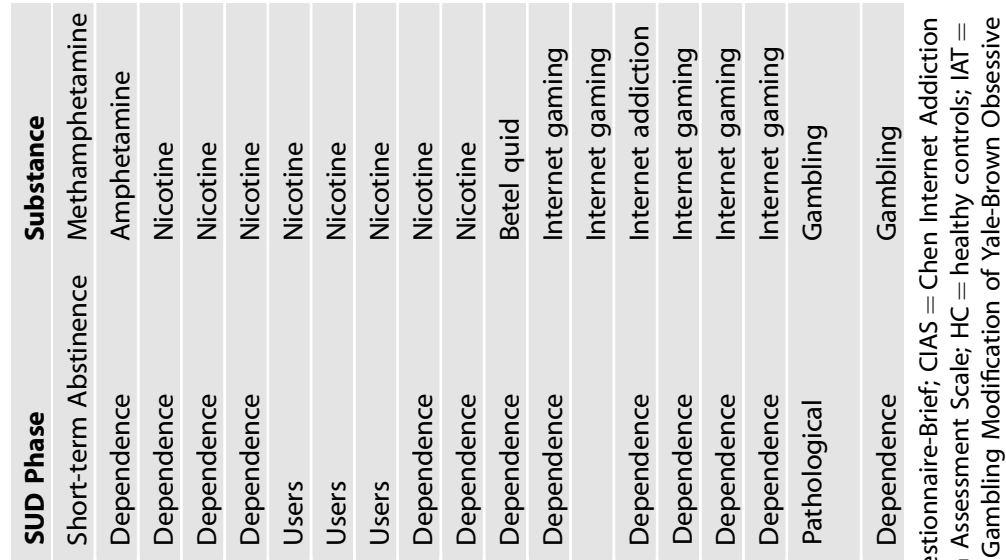

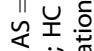

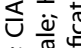

ษั

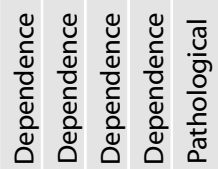

๑ั

完 है

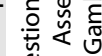

đั

ํㅡㄹ है

\ุ.

จิ ลิ ^
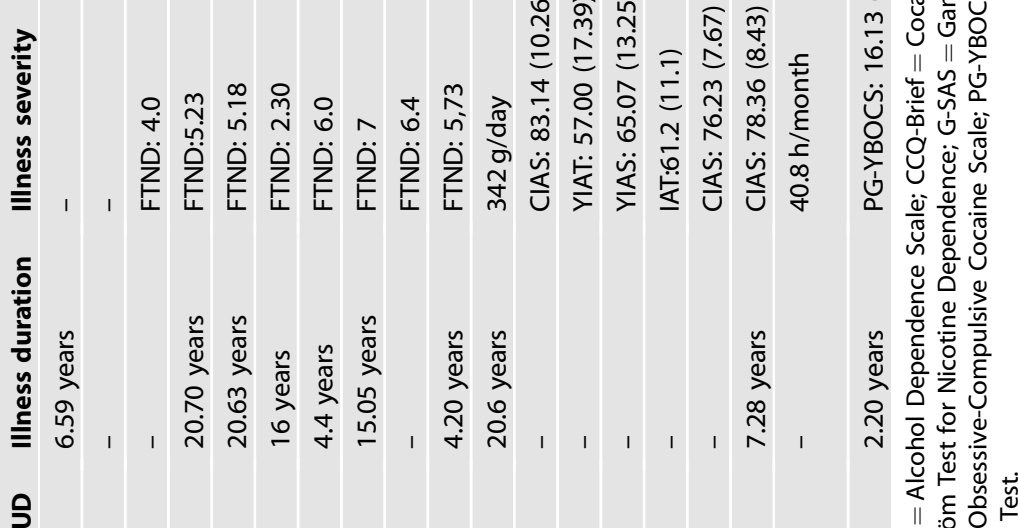

๘)

ஜ ๘

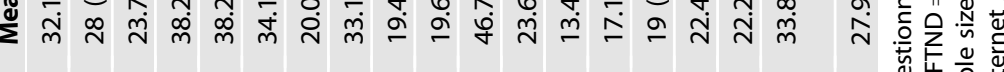

$\Xi$ वे छे

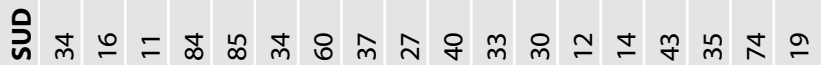

in $\underset{\overbrace{}}{\stackrel{5}{\leftrightarrows}}$

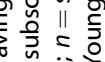

ư

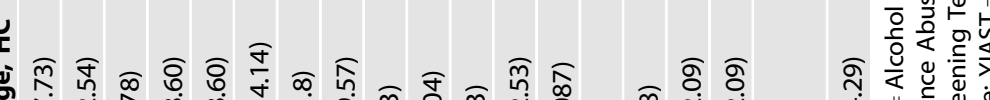

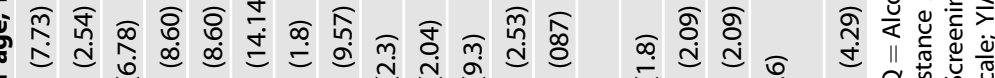

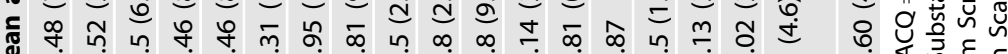

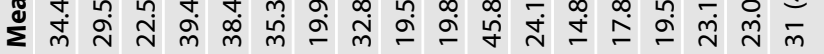

$\underline{\mathbf{s}}$

ํำ $\bar{n}$ 워

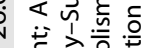

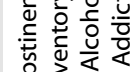

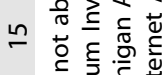
离

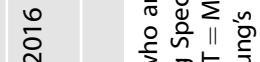
t

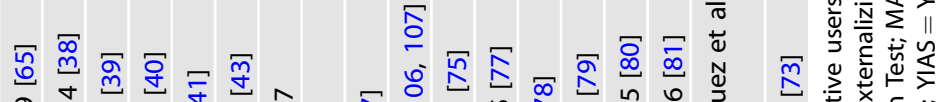

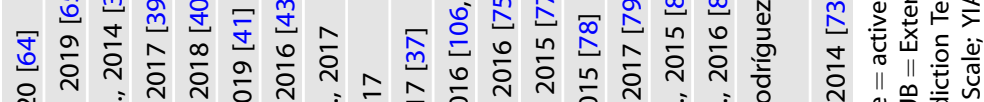

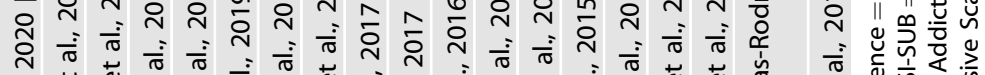

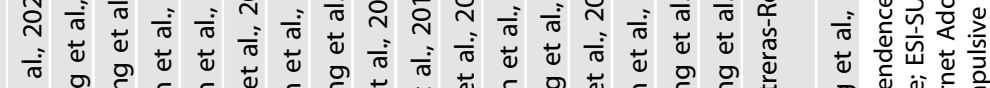

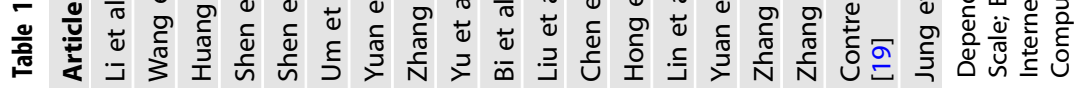


2. To compare group differences in seed-based functional connectivity among $\mathrm{BA}-\mathrm{HC}$ were examined using the results of between-group contrasts $(B A<H C$ and $B A>H C)$, respectively.

Effects were categorized based on the direction of effect (hyperconnectivity or hypoconnectivity in SUD or BA). Hyperconnectivity has been defined as larger positive or reduced negative rsFC and hypoconnectivity as larger negative or reduced positive $\mathrm{rsFC}$ compared with healthy controls.

\section{Study eligibility criteria}

Studies focusing on other psychiatric comorbidities, such as depression, schizophrenia, anxiety, obsessive-compulsive disorder and neurological conditions were excluded as they have been separated in the DSM-V [30]. In the first screening of articles, the titles and abstracts were considered, and the following exclusion criteria were applied: (1) non-empirical studies, (2) non-human studies, (3) non-fMRI studies, (4) non-rsFC studies, (5) nonsubstance use disorder studies and (6) no adults. Subsequently, the full text of every article was further evaluated for eligibility. Studies were also excluded due to (1) not in English, (2) no HC group, (3) entries having the same seed regions of interest reported in another publication. These searches and exclusion criteria yielded a sample, $n=1911$ for SUD + BA and $n=1580$ for controls (Table 1). Coordinates were reported either in Talairach or Montreal Neurology Institute (MNI) coordinate space. The final dataset included seventy-two articles for SUD and BA > HC (310 contrasts) and seventy-two articles for the HC > SUD and BA (283 contrasts).

\section{Meta-analysis}

GingerALE is a freely available, quantitative meta-analysis method developed by Turkeltaub et al [31] with the latest version described by Eickhoff and colleagues [28, 32] and Turkeltaub and colleagues [33]. Here, the latest version of GingerALE (3.0.2) was used (The BrainMap Database, www. brainmap.org; San Antonio, TX, USA), which relies on activation likelihood estimation (ALE) to compare coordinates compiled from multiple articles, estimate the magnitude of overlap, and yield clusters most statistically likely to become active across studies. The algorithm minimizes within-group effects and provides increased power by allowing for the inclusion of all relevant experiments $[28,33]$. Talairach coordinates were converted to MNI with the Lancaster and colleagues (2007) transformation algorithm. Coordinates in MNI space were imported into the software. Imported foci were modeled using a full-width at half-maximum (FWHM) kernel estimated based on the corresponding experiment's sample size as three-dimensional Gaussian spatial probability distributions [28, 33]. The resulting statistical maps were thresholded at $p<0.05$ using a cluster-level correction for multiple comparisons and a cluster threshold at $p<0.05$ [28]. Group differences were examined using contrast analyses. The threshold for group-contrasts was set to $p<0.05$ uncorrected for multiple comparisons with 5000 permutations [34]. Group differences in resting-state functional connectivity were examined using the following six contrasts in ALE analyses: $\mathrm{SUD}+\mathrm{BA}>\mathrm{HC}$ and SUD $+\mathrm{BA}<\mathrm{HC} ; \mathrm{SUD}>\mathrm{HC}$ and $\mathrm{SUD}<\mathrm{HC} ; \mathrm{BA}>\mathrm{HC}$ and $\mathrm{BA}<\mathrm{HC} ; \mathrm{SUD}>\mathrm{BA}$ and $\mathrm{SUD}<\mathrm{BA}$.

\section{MKDA}

Multilevel kernel density analysis (MKDA) was implemented through Matlab toolbox NeuroElf (http://neuroelf.net/) consistently with MKDA neuroimaging meta-analytic procedures $[35,36]$. Contrast coordinates in Talaraich space were converted to MNI space. For all analyses, we used a priori threshold of $p<0.05$ (family-wise error-corrected for multiple comparisons). Specifically, we investigated these meta-analytic contrasts as follow: [SUD $>\mathrm{HC}$ and $\mathrm{SUD}<\mathrm{HC}$ ] and $[\mathrm{BA}>\mathrm{HC}$ and $\mathrm{BA}<\mathrm{HC}$.

\section{RESULTS}

\section{Included studies and sample characteristics}

Meta-analyses were performed using GingerALE and consist of individuals with SUD (1911 subjects) and healthy controls (1580), both of which satisfied ALE power recommendations and include a minimum of 17 contrasts [28]. The mean age for SUD individuals and for healthy controls was $33.24( \pm 6.16)$ and $34.28( \pm 5.99)$ years old, respectively. See Supplementary Table S1 for more information regarding the rsFC methodology of the studies included in the meta-analyses.
For the SUD group, eight studies reported participants with nicotine addiction [37-44] and eight articles reported participants with alcoholism and/or harmful drinking habits [36-39, 42, 44, 45]. Four studies reported participants [46-49] who were cannabis users and 13 studies reported participants who were cocaine users $[19,50-60]$. The remaining articles on SUD reported a variety of stimulants including methamphetamine/amphetamine $(n=5)$ [61-65], and heroin/methadone $(n=12)$ [66-71]. For the BA group, three articles reported participants with pathological gambling disorder [72-74] and eight studies reported participants with internet gaming disorder $[66,75-81]$.

\section{Meta-analytic resting-state functional connectivity}

SUD results. A total of forty-four studies investigating rsFC abnormalities in SUD patients were identified. Table 3 shows a complete list of the independent meta-analysis of rSFC on SUD and $\mathrm{HC}$ only (ALE values are listed in Table 2).

The rsFC meta-analysis in SUD, when compared with $\mathrm{HC}$, revealed the largest hyperconnectivity cluster to be within the striatum (putamen, caudate) and middle frontal gyrus (dorsolateral prefrontal cortex or DLPFC) (Fig. 2A and B). This was followed by a relatively large globus pallidus and anterior cingulate cluster and thalamus, as well as medial frontal gyrus (ventromedial prefrontal cortex or VMPFC) for the largest hypoconnectivity cluster (See Table 2).

$B A$ Results. A total of eight studies investigating rsFC abnormalities in BA patients were identified. The majority of the identified studies investigated pathological gambling addiction and the remaining three studies investigated $\mathrm{rsFC}$ in internet gaming disorder. Table 2 shows a complete list of brain connectivity for independent meta-analyses on BA and HC (ALE values are listed in Table 2). The rsFC meta-analysis in BA included hyperconnectivity in regions within the putamen, amygdala, and medial frontal gyrus (Fig. 2C and D), and hypoconnectivity in the caudate, cingulate, and thalamus.

Conjunction and contrast analyses: SUD and BA Results. Conjunction and contrast analyses were performed to assess whether addiction specificity was present, based on previous reviews $[26,27]$. While the conjunction analysis revealed hyperconnectivity for both SUD and BA in the putamen, the contrast analysis revealed hyperconnectivity in the claustrum, caudate, putamen and anterior cingulate for SUD (largest cluster size 8112) when compared with BA. The putamen/caudate and insula had the greatest hyperconnectivity cluster size in BA when compared with SUD (largest cluster size 1544). Hypoconnectivity for SUD and BA was shown in the medial frontal gyrus and thalamus. Hypoconnectivity within the temporal lobe was shown in SUD when compared with BA. The medial frontal gyrus and anterior cingulate revealed hypoconnectivity in BA when compared with SUD (ALE values are listed in Table 2).

SUD $+B A$ Results. A total of seventy-two studies investigating rsFC abnormalities in SUD + BA were identified. Table 2 shows a complete list of brain activities for independent meta-analyses on SUD + BA and HC. Data from each cluster are listed in order of cluster size in MNI space identified by all ALE meta-analyses. Higher ALE values are indicative of a greater likelihood of rsFC (ALE values are listed in Table 3 ).

For SUD + BA, the meta-analysis revealed that the largest hyperconnectivity cluster was within the amygdala, thalamus, and midbrain (Fig. 3) and relatively large parahippocampal gyrus, caudate, and putamen cluster, as well as hypoconnectivity in the posterior lobe and parahippocampal gyrus. For $\mathrm{HC}$, the rsFC metaanalysis showed hyperconnectivity in the thalamus, midbrain, cingulate and frontal lobe and hypoconnectivity within the pa rietal lobe and cerebellum. The contrast analysis revealed 
Table 2. Results of the meta-analysis of resting-state functional connectivity in SUD and BA.

\begin{tabular}{|c|c|c|c|c|c|c|c|}
\hline Cluster & Cluster size $\left(\mathrm{mm}^{3}\right)$ & Brain regions & BA & $x$ & $y$ & $z$ & ALE \\
\hline \multicolumn{8}{|c|}{$S U D>H C$} \\
\hline \multirow[t]{4}{*}{1} & 18,160 & L Putamen & & -20 & 16 & -6 & 0.0220 \\
\hline & & L Caudate & & -10 & 16 & -2 & 0.0200 \\
\hline & & L Middle Frontal Gyrus & 44 & -44 & 18 & 26 & 0.0200 \\
\hline & & L Insula & & -34 & -6 & 20 & 0.0100 \\
\hline 2 & 7200 & R Putamen & & 26 & 6 & 4 & 0.0200 \\
\hline \multicolumn{8}{|c|}{$B A>H C$} \\
\hline \multirow[t]{2}{*}{1} & 20,592 & R Putamen & & 26 & 6 & -12 & 0.0110 \\
\hline & & R Amygdala & 21 & 48 & -10 & -12 & 0.0110 \\
\hline \multicolumn{8}{|c|}{$S U D<H C$} \\
\hline 1 & 10,000 & L Thalamus & & -8 & -14 & 2 & 0.0168 \\
\hline \multirow[t]{2}{*}{1} & 14,416 & R Medial Frontal Gyrus & 9 & 22 & 46 & 18 & 0.0100 \\
\hline & & R Anterior Cingulate & 32 & 4 & 24 & 42 & 0.0090 \\
\hline \multirow[t]{2}{*}{2} & 12,328 & L Thalamus & & -6 & -8 & 12 & 0.0090 \\
\hline & & R Caudate & & 6 & 6 & 0 & 0.0090 \\
\hline \multicolumn{8}{|c|}{$S U D \cap B A^{+}$} \\
\hline 1 & 2584 & R Putamen & & 18 & 4 & 8 & 0.0096 \\
\hline \multicolumn{8}{|c|}{ SUD $>\boldsymbol{B A}^{+}$} \\
\hline \multirow[t]{2}{*}{1} & 8112 & L Claustrum & & -30.2 & 17.2 & 4.1 & 0.1000 \\
\hline & & L Caudate & & -10.9 & 19.5 & -5.6 & 0.1000 \\
\hline 1 & 3168 & R Medial Frontal Gyrus & 6 & 0 & 36 & 32 & 0.0090 \\
\hline 2 & 1904 & L Thalamus & & -24 & -20 & 4 & 0.0090 \\
\hline \multicolumn{8}{|c|}{$S U D<B A^{-}$} \\
\hline 1 & 272 & L Temporal Lobe & 38 & -48.9 & 4.1 & -19.8 & 0.0400 \\
\hline \multicolumn{8}{|c|}{$B A<S U D^{-}$} \\
\hline 1 & 88 & R Medial Frontal Gyrus & 9 & 14.9 & 50.7 & 14.4 & 0.0500 \\
\hline 2 & 24 & R Anterior Cingulate & 32 & 12 & 45.3 & 8.7 & 0.0500 \\
\hline
\end{tabular}

MNI coordinates $(x, y, z)$ of brain regions surviving a cluster-level threshold of $p<0.05$ and a cluster forming threshold of $p<0.05$ for single studies. Contrast threshold was set to $p=0.05,5000$ permutations, $>50 \mathrm{~mm}^{3}, \mathrm{ALE}=$ Activation Likelihood Estimate; $\mathrm{BA}=$ Brodmann Area; $\mathrm{BA}=\mathrm{Behavioral}$ Addiction; $\mathrm{HC}=$

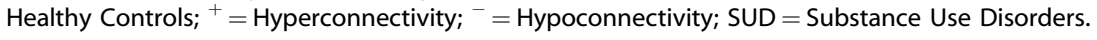

hyperconnectivity in the basal ganglia, thalamus, insula, amygdala, and parahippocampal gyrus in SUD + BA in comparison with $\mathrm{HC}$ (See Table 3 for further details). MKDA results for SUD vs controls, and BA vs controls, are displayed in Fig. 4.

\section{DISCUSSION}

The need to better describe the human brain connectivity in SUD and BA has long been recognized, whereby meta-analyses serve as a crucial tool for consolidating evidence and streamlining the prevalent narrative (for a recent perspective see Suckling and
Nestor, 2017; Yip et al., 2017) [18, 82]. To our knowledge, no previous meta-analysis has examined how connections between different brain areas during rest are altered in addictive neuropathologies. Here, we aimed to apply the ALE metaanalysis method to estimate convergence in functional connectivity rs-fMRI-based FC in substance use and behavioral disorders across studies.

We integrated findings from seventy-two rsFC studies and found convergent hyperconnectivity in individuals with SUD and/ or BA: in the amygdala-basal ganglia, thalamus-midbrain and hypoconnectivity in the posterior lobe. In addition, basal ganglia, 


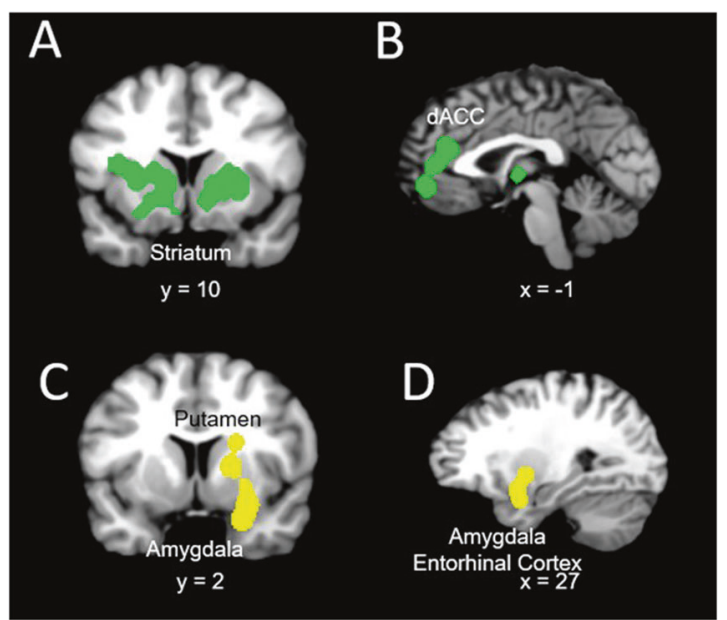

Fig. 2 Concordant activation across SUD and BA. A, B: regions concordant across studies for SUD (in green) and C, D: regions concordant across studies for BA (in yellow). insula, amygdala and parahippocampal gyrus exhibited hyperconnectivity in the SUD group compared with the healthy control group. These findings show the enhancement of connectivity in the reward and salience networks, suggesting that altered physiology in the basal ganglia, midbrain, insula and mediotemporal lobe might be evaluated as specific biomarkers for drug addictions [3]. Interestingly, and importantly, our findings are consistent with an earlier systematic review of rsFC brain connectivity in drug addiction [17], which proposed that nicotine addiction had salience and executive network altered. This was confirmed by another recent review on chronic stimulant users which found enhanced coupling of reward, salience, and memory networks [83]. The hyperconnectivity of the reward and salience network in our meta-analysis might suggest that the recruited patients might be in a more chronic state of addiction [83]. The current meta-analysis expands upon previous results on specific brain regions by showing that abnormality in larger brain networks might be present in addiction.

Another novel finding of our ALE meta-analysis is the convergence of intrinsic functional patterns in the putamen in the SUD and BA, compared to HC. Numerous human and animal studies have identified putamen as the key region in SUD and HC,

Table 3. Results of the meta-analysis of resting-state functional connectivity in SUD + BA and controls.

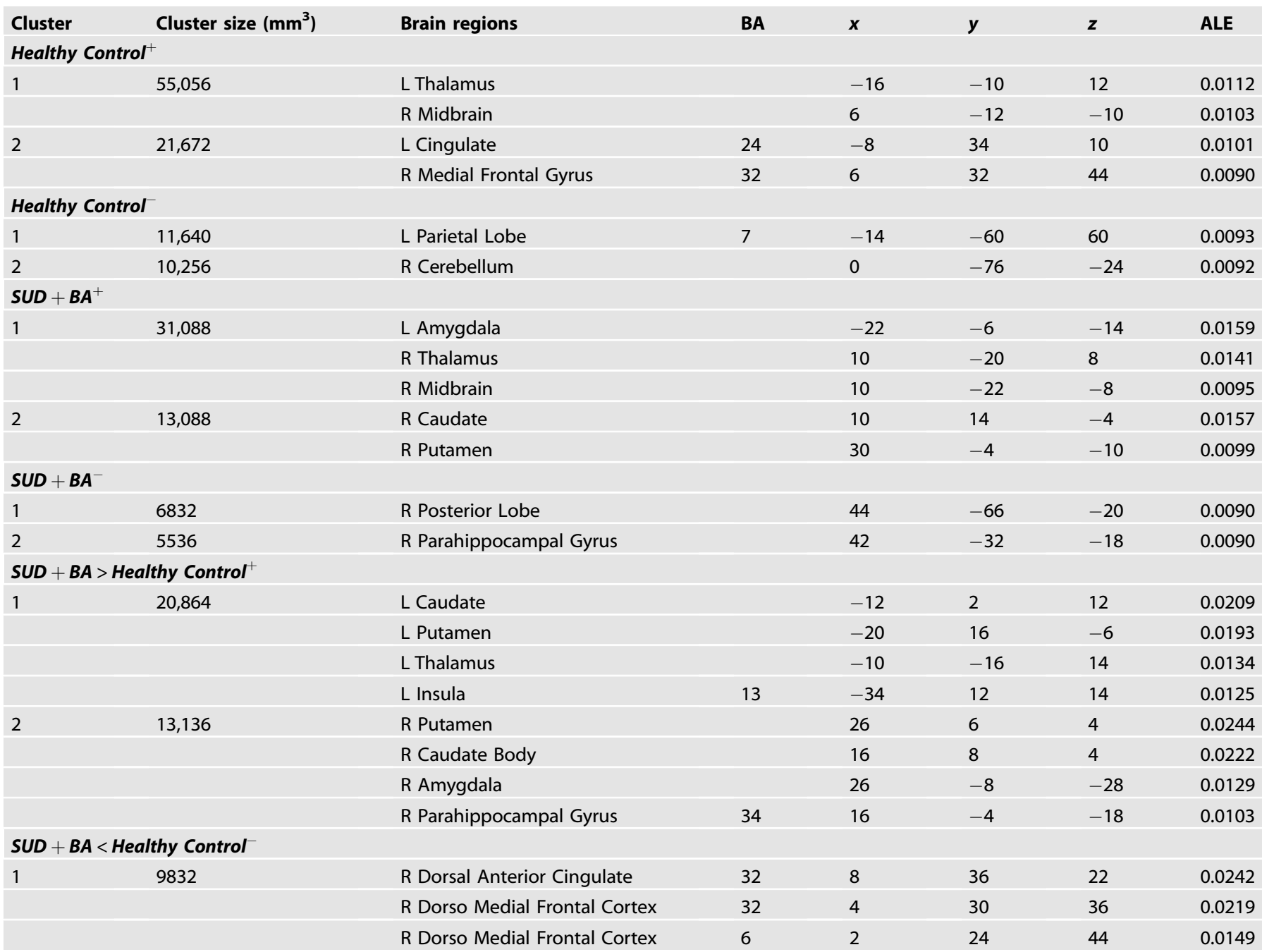

MNI coordinates $(x, y, z)$ of brain regions surviving a cluster-level threshold of $p<0.05$ and a cluster forming threshold of $p<0.05$ for single studies. Contrast threshold was set to $p=0.05,5000$ permutations, $>50 \mathrm{~mm}^{3}, \mathrm{ALE}=$ Activation Likelihood Estimate; $\mathrm{BA}=$ Brodmann Area; ${ }^{+}=\mathrm{Hyperconnectivity;}^{-}=$ Hypoconnectivity. 


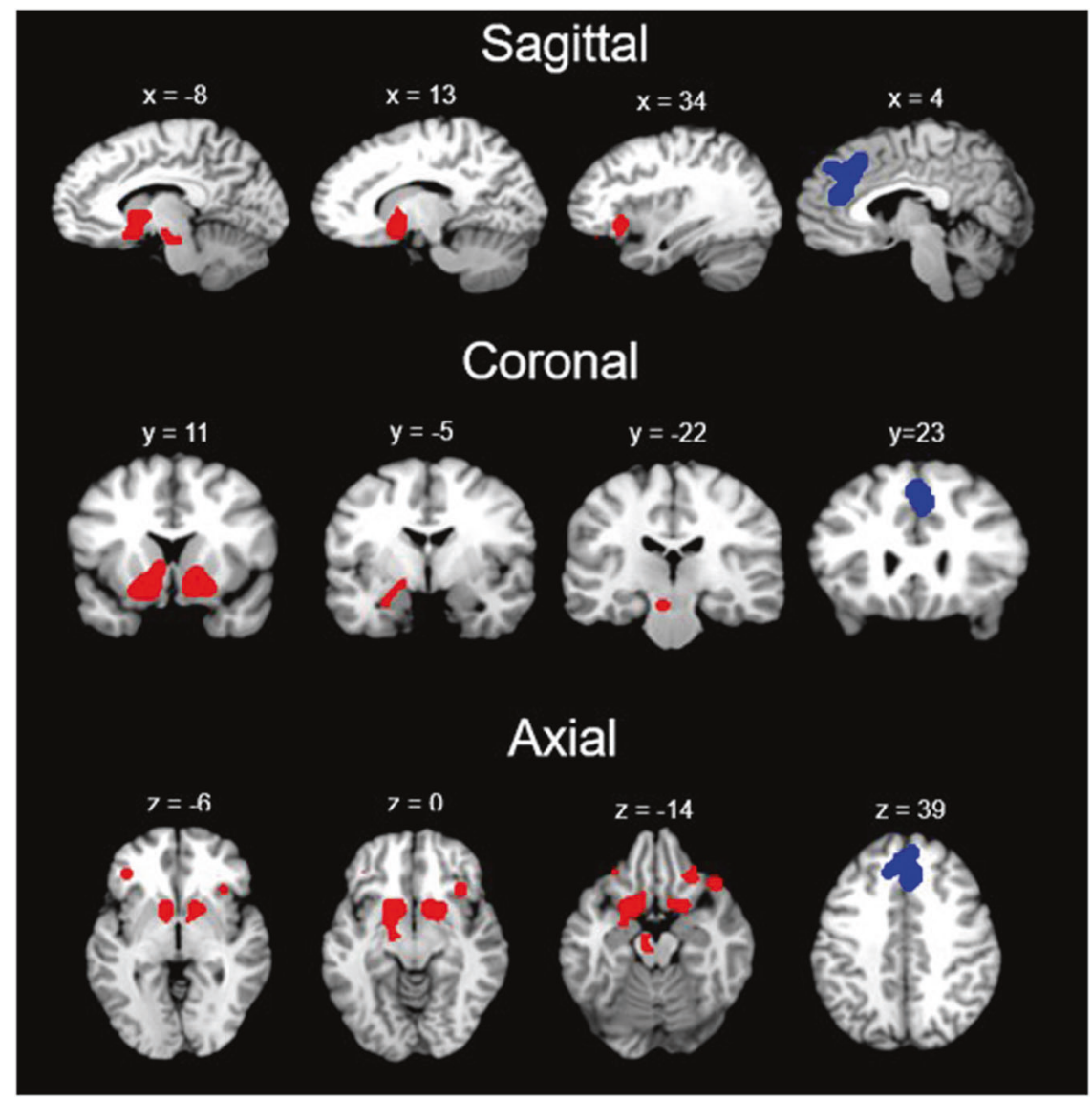

Fig. 3 Concordant connectivity across SUD and BA. Concordant hyperconnectivity (red) and hypoconnectivity (blue) across SUD and BA (Sagittal, Coronal and Axial views).
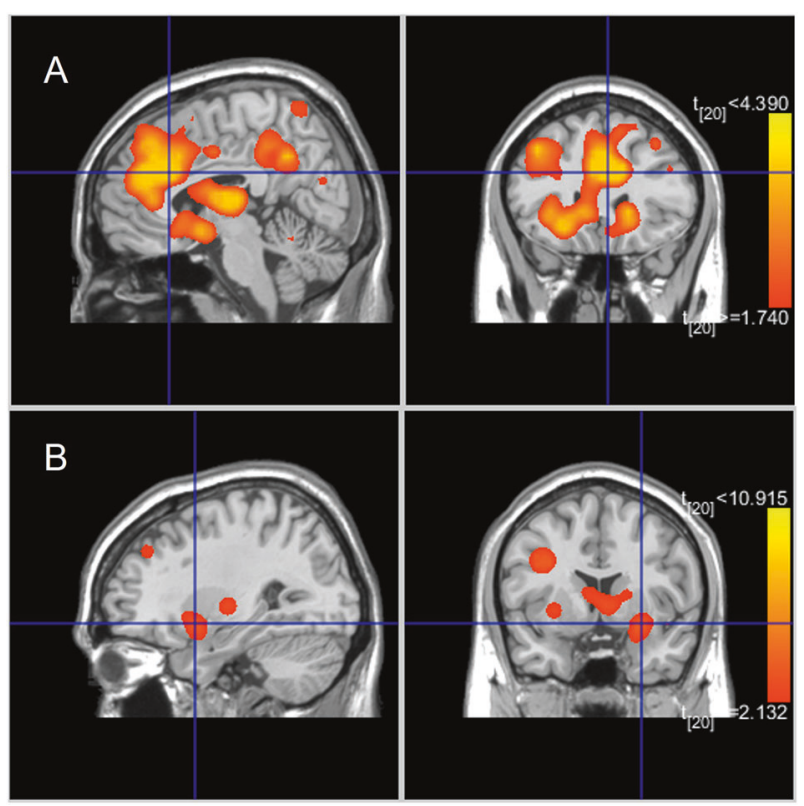

Fig. 4 MKDA findings. Results from the MKDA analyses. A SUD vs controls and (B) BA vs controls.

given its role in a variety of functions encompassing higher motor control, impulsivity and inhibitory control [77, 84-86]. In BA, a selective involvement of putamen functional connectivity in internet gaming disorder was revealed [77]. In addition, the putamen is part of the striatal "habit network" underlying learning of automatic behavior [19, 72].

Interestingly, no previous rsFC study has compared SUD and BA to probe the neural specificity. No studies have directly provide neural evidence to support the idea of addiction specificity [26, 27]. Here, we found that SUD showed hyperconnectivity in the basal ganglia (putamen, caudate, and globus pallidus), claustrum, middle frontal gyrus, and anterior cingulate compared with healthy controls. Instead, $\mathrm{BA}$ revealed hyperconnectivity in the putamen, temporal and frontal lobe. We suggest that the basal ganglia, claustrum and anterior cingulate are neuroanatomical substrates linked with SUD, which showed increased connectivity compared with BA. The importance of these regions in encoding rewards and/or reward-seeking and cognitive control has been demonstrated by functional imaging and human lesion studies [52, 87-90]. These increased connectivities for SUD adds further support to their central role specifically in the chronic phase of the addiction cycle. Much evidence exists on the capacity of drugs to enhance the mesolimbic dopamine system, whilst there is much less evidence in BA [52, 91-93].

Although our findings integrated a remarkably large sample size to establish consensus on the location of network disruptions in drug and behavioral addictions, limitations should be considered. First, the golden standard for directly detecting monosynaptic axonal pathways is the chemical tracer technique which requires ex-vivo tissue processing and can only be acquired in animal studies [94]. Thus, it is unclear how rsFC reflects the strength of monosynaptic and polysynaptic pathways. Second, the seventytwo experiments included in our meta-analysis differ in design, methodology, age, gender of the population, illness severity and duration of the use patterns (See Table 1 for further details). The wide variation of the substances used, and measures of quantity 
illustrate the need to report these factors more thoroughly and systematically in future studies. In addition, it highlights the need to standardize the reporting in future studies. Third, although the functional significance of positive and negative rsFC remains unclear, we lumped higher positive rsFC and lower negative rsFC in the SUD/BA vs. HC contrast, making it difficult to differentiate whether the differences were driven by higher rsFC in one group or lower rsFC in another group. The majority of studies only reported group differences without providing details about positive/negative rsFC in each group. Further studies may further explore the nature of group differences in rsFC.

Notably, there are several explanations for group differences in functional connectivity. It is possible that both groups may show positive functional connectivity and one group exhibits stronger positive functional connectivity than the other group. It is also possible that both groups show negative functional connectivity and one group exhibits weaker negative connectivity than the other group. The third possibility is that one group shows positive functional connectivity and the other group shows negative functional connectivity and hence there is a significant group difference. Unfortunately, in many of the original studies, the functional connectivity patterns in each group were not always reported. Hence, the current study cannot do separate withingroup ALE analyses, e.g., one ALE analysis for positive connectivity in SUD group and one ALE analysis for negative connectivity in SUD group. We suggest that future empirical studies should aim to routinely report functional connectivity for each group before reporting group differences. Such practice might help researchers understand the nature of group differences and the pathophysiology of mental illnesses, including addictive disorders.

Fourth, due to the limited number of studies included we aggregated studies with heterogeneous patients, ranging from initial to abstinence stage, from short to long-term addictions. Analysis of subtypes of addictions and their cognitive functions and behavioral changes would be a strong supplement and would provide more context for each brain network. In the future, a meta-analysis with ReHo [95], ICA [96], ALFF and graph analysis studies is warranted.

In conclusion, the findings of this meta-analysis suggest that rsFC connectivity in drug and behavioral addictions are disrupted. Altered hyperconnectivity within salience or emotion processing may relate to deficits in regulating increased sensitivity to reward and salience stimuli. These findings might be helpful when attempting to identify potential putative markers for pharmacological interventions. A priority for future research would be to further identify how these unbalanced networks impact different phases (inclusive of intoxication, withdrawal and dependence) of the addiction cycle. These results might be used as indicatives of high risk in developing SUD or BA and might potentially guide effective treatments at an early stage.

\section{REFERENCES}

1. Koob GF, Volkow ND. Neurocircuitry of addiction. Neuropsychopharmacology. 2010;35:217-38.

2. Koob GF, Volkow ND. Neurobiology of addiction: a neurocircuitry analysis. Lancet Psychiatry. 2016;3:760-73.

3. Zilverstand A, Huang AS, Alia-Klein N, Goldstein RZ, Review Neuroimaging impaired response inhibition and salience attribution in human drug addiction: a systematic review. 2018. https://doi.org/10.1016/j.neuron.2018.03.048.

4. Luijten M, Schellekens AF, Kühn S, Machielse MWJ, Sescousse G. Disruption of reward processing in addiction. JAMA Psychiatry. 2017;74:387-398.

5. Tolomeo S, Yaple ZA, Yu R, Neural representation of prediction error signals in substance users. Addict Biol. 2020. https://doi.org/10.1111/adb.12976.

6. Kareken DA, Grahame N, Dzemidzic M, Walker MJ, Lehigh CA, O'Connor SJ. fMRI of the brain's response to stimuli experimentally paired with alcohol intoxication. Psychopharmacology. 2012;220:787-97.

7. Gu X, Lohrenz T, Salas R, Baldwin PR, Soltani A, Kirk U, et al. Belief about nicotine selectively modulates value and reward prediction error signals in smokers. Proc Natl Acad Sci USA. 2015;112:2539-44.
8. Langleben DD, Ruparel K, Elman I, Busch-Winokur S, Pratiwadi R, Loughead J, et al. Acute effect of methadone maintenance dose on brain fMRI response to heroin-related cues. Am J Psychiatry. 2008;165:390-4.

9. Liu S, Wang S, Zhang M, Xu Y, Shao Z, Chen L, et al. Brain responses to drug cues predict craving changes in abstinent heroin users: a preliminary study. Neuroimage. 2021;237:118169.

10. Brandl F, Avram M, Weise B, Shang J, Simões B, Bertram T, et al. Specific substantial dysconnectivity in schizophrenia: a transdiagnostic multimodal metaanalysis of resting-state functional and structural magnetic resonance imaging studies. Biol Psychiatry. 2019;85:573-83.

11. Kaiser RH, Andrews-Hanna JR, Wager TD, Pizzagalli DA. Large-scale network dysfunction in major depressive disorder: a meta-analysis of resting-state functional connectivity. JAMA Psychiatry. 2015;72:603-11.

12. Tahmasian M, Eickhoff SB, Giehl K, Schwartz F, Herz DM, Drzezga A, et al Resting-state functional reorganization in Parkinson's disease: an activation likelihood estimation meta-analysis. Cortex 2017;92:119-38.

13. Biswal BB. Resting state fMRI: a personal history. Neuroimage 2012;62:938-44.

14. Fedota JR, Stein EA. Resting-state functional connectivity and nicotine addiction: prospects for biomarker development. Ann N. Y Acad Sci. 2015;1349:64-82.

15. leong $\mathrm{HFH}$, Yuan Z, Resting-state neuroimaging and neuropsychological findings in opioid use disorder during abstinence: a review. Front Hum Neurosci. 2017; 11. https://doi.org/10.3389/fnhum.2017.00169.

16. Pariyadath V, Gowin JL, Stein EA, Resting state functional connectivity analysis for addiction medicine: from individual loci to complex networks. In: Progress in brain research. Elsevier B.V., 2016, pp 155-73.

17. Sutherland MT, McHugh MJ, Pariyadath V, Stein EA. Resting state functional connectivity in addiction: lessons learned and a road ahead. Neuroimage 2012;62:2281-95.

18. Yip SW, Morie KP, Xu J, Constable RT, Malison RT, Carroll KM, et al. Shared microstructural features of behavioral and substance addictions revealed in areas of crossing fibers. Biol Psychiatry Cogn Neurosci Neuroimaging. 2017;2:188-95.

19. Contreras-Rodríguez O, Albein-Urios N, Vilar-López R, Perales JC, MartínezGonzalez JM, Fernández-Serrano MJ, et al. Increased corticolimbic connectivity in cocaine dependence versus pathological gambling is associated with drug severity and emotion-related impulsivity. Addict Biol. 2016;21:709-18.

20. Lim KO, Choi SJ, Pomara N, Wolkin A, Rotrosen JP. Reduced frontal white matter integrity in cocaine dependence: a controlled diffusion tensor imaging study. Biol Psychiatry. 2002;51:890-5.

21. Moeller FG, Hasan KM, Steinberg JL, Kramer LA, Dougherty DM, Santos RM, et al. Reduced anterior corpus callosum white matter integrity is related to increased impulsivity and reduced discriminability in cocaine-dependent subjects: diffusion tensor imaging. Neuropsychopharmacology. 2005;30:610-7.

22. Yip SW, Lacadie C, Xu J, Worhunsky PD, Fulbright RK, Constable RT, et al Reduced genual corpus callosal white matter integrity in pathological gambling and its relationship to alcohol abuse or dependence. World J Biol Psychiatry. 2013;14:129-38

23. Joutsa J, Saunavaara J, Parkkola R, Niemelä S, Kaasinen V. Extensive abnormality of brain white matter integrity in pathological gambling. Psychiatry ResNeuroimaging. 2011;194:340-6.

24. Mohammadi B, Hammer A, Miedl SF, Wiswede D, Marco-Pallarés J, Herrmann M, et al. Intertemporal choice behavior is constrained by brain structure in healthy participants and pathological gamblers. Brain Struct Funct. 2016;221:3157-70.

25. Grant JE, Odlaug BL, Chamberlain SR. Reduced cortical thickness in gambling disorder: a morphometric MRI study. Eur Arch Psychiatry Clin Neurosci. 2015;265:655-61.

26. Sussman S, Lisha N, Griffiths M. Prevalence of the addictions: a problem of the majority or the minority? Eval Heal Prof. 2011;34:3-56.

27. Sussman $S$, Leventhal A, Bluthenthal RN, Freimuth $M$, Forster $M$, Ames SL. A framework for the specificity of addictions. Int J Environ Res Public Health. 2011;8:3399-415.

28. Eickhoff SB, Laird AR, Fox PM, Lancaster JL, Fox PT. Implementation errors in the GingerALE software: description and recommendations. Hum Brain Mapp. 2017;38:7-11.

29. TD Wager, MA Lindquist, TE Nichols, H Kober, JX Van Snellenberg, Evaluating the consistency and specificity of neuroimaging data using meta-analysis. Neuroimage 2009; 45. https://doi.org/10.1016/J.NEUROIMAGE.2008.10.061.

30. American Psychiatric Association. DSM-V. 2013 https://doi.org/10.1176/appi. books.9780890425596.744053.

31. Turkeltaub PE, Eden GF, Jones KM, Zeffiro TA. Meta-analysis of the functional neuroanatomy of single-word reading: method and validation. Neuroimage. 2002:16:765-80.

32. Eickhoff SB, Laird AR, Grefkes C, Wang LE, Zilles K, Fox PT. Coordinate-based activation likelihood estimation meta-analysis of neuroimaging data: a randomeffects approach based on empirical estimates of spatial uncertainty. Hum Brain Mapp. 2009:30:2907-26. 
33. Turkeltaub PE, Eickhoff SB, Laird AR, Fox $M$, Wiener M, Fox P. Minimizing withinexperiment and within-group effects in activation likelihood estimation metaanalyses. Hum Brain Mapp. 2012;33:1-13.

34. Sokolowski HM, Fias W, Mousa A, Ansari D. Common and distinct brain regions in both parietal and frontal cortex support symbolic and nonsymbolic number processing in humans: a functional neuroimaging meta-analysis. Neuroimage. 2017;146:376-94.

35. Kober H, Wager TD. Meta-analysis of neuroimaging data. Wiley Interdiscip Rev Cogn Sci. 2010;1:293-300.

36. Wager TD, Lindquist $M$, Kaplan L. Meta-analysis of functional neuroimaging data: current and future directions. Soc Cogn Affect Neurosci. 2007;2:150-8.

37. Bi Y, Yuan K, Guan Y, Cheng J, Zhang Y, Li Y, et al. Altered resting state functional connectivity of anterior insula in young smokers. Brain Imaging Behav. 2017;11:155-65.

38. Huang W, King JA, Ursprung WWS, Zheng S, Zhang N, Kennedy DN, et al. The development and expression of physical nicotine dependence corresponds to structural and functional alterations in the anterior cingulate-precuneus pathway. Brain Behav. 2014;4:408-17.

39. Shen Z, Huang P, Wang C, Qian W, Luo X, Guan X, et al. Altered function but not structure of the amygdala in nicotine-dependent individuals. Neuropsychologia. 2017;107:102-7.

40. Shen Z, Huang P, Wang C, Qian W, Yang Y, Zhang M. Cerebellar gray matter reductions associate with decreased functional connectivity in nicotinedependent individuals. Nicotine Tob Res. 2018;20:440.

41. Um M, Hummer TA, Cyders MA. Relationship of negative urgency to cinguloinsular and cortico-striatal resting state functional connectivity in tobacco use. Brain Imaging Behav. 2020;14:1921-32.

42. Yu D, Yuan K, Bi Y, Luo L, Zhai J, Liu B, et al. Altered interhemispheric restingstate functional connectivity in young male smokers. Addict Biol. 2018;23:772-80.

43. Yuan K, Yu D, Bi Y, Li Y, Guan Y, Liu J, et al. The implication of frontostriatal circuits in young smokers: a resting-state study. Hum Brain Mapp. 2016;37:2013-26.

44. Sheng Z, Sien $H$, Lisa MF, Xingguang L, Carolyn MM, Laszlo Z, et al. Resting-state functional connectivity of the basal nucleus of meynert in cigarette smokers: dependence level and gender differences. Nicotine Tob Res. 2017; 19. https:// doi.org/10.1093/NTR/NTW209.

45. Camchong J, Stenger A, Fein G. Resting-state synchrony in long-term abstinent alcoholics. Alcohol Clin Exp Res. 2013;37:75-85.

46. Blanco-Hinojo L, Pujol J, Harrison BJ, Macià D, Batalla A, Nogué S, et al. Attenuated frontal and sensory inputs to the basal ganglia in cannabis users. Addict Biol. 2017;22:1036-47.

47. Orr C, Morioka R, Behan B, Datwani S, Doucet M, Ivanovic J, et al. Altered restingstate connectivity in adolescent cannabis users. Am J Drug Alcohol Abus. 2013;39:372-81.

48. Pujol J, Blanco-Hinojo L, Batalla A, López-Solà M, Harrison BJ, Soriano-Mas C, et al. Functional connectivity alterations in brain networks relevant to selfawareness in chronic cannabis users. J Psychiatr Res. 2014;51:68-78.

49. Zhou F, Zimmermann K, Xin F, Scheele D, Dau W, Banger M, et al. Shifted balance of dorsal versus ventral striatal communication with frontal reward and regulatory regions in cannabis-dependent males. Hum Brain Mapp. 2018;39:5062-73.

50. Adinoff B, Gu H, Merrick C, McHugh M, Jeon-Slaughter $H$, Lu H, et al. Basal hippocampal activity and its functional connectivity predicts cocaine relapse. Biol Psychiatry. 2015;78:496-504.

51. Geng X, Hu Y, Gu H, Salmeron B, Adinoff B, Brain ES, et al. Salience and default mode network dysregulation in chronic cocaine users predict treatment outcome. academic.oup.com https://academic.oup.com/brain/article-abstract/140/ 5/1513/3038013 (Accessed 1 June 2020).

52. Gu H, Salmeron BJ, Ross TJ, Geng X, Zhan W, Stein EA, et al. Mesocorticolimbic circuits are impaired in chronic cocaine users as demonstrated by resting-state functional connectivity. Neuroimage. 2010;53:593-601.

53. Hu Y, Salmeron BJ, Gu H, Stein EA, Yang Y. Impaired functional connectivity within and between frontostriatal circuits and its association with compulsive drug use and trait impulsivity in cocaine addiction. JAMA Psychiatry. 2015;72:584-92.

54. Kelly C, Zuo XN, Gotimer K, Cox CL, Lynch L, Brock D, et al. Reduced interhemispheric resting state functional connectivity in cocaine addiction. Biol Psychiatry. 2011;69:684-92.

55. Martins DLN, Valiatti TD, de S, D'Ávila J, Ferreira LF, Batista EK, et al. A conectividade funcional extrínseca da rede de modo padrão em usuários de crackcocaína. Radio Bras. 2018;51:1-7.

56. McHugh MJ, Demers CH, Salmeron BJ, Devous MD, Stein EA, Adinoff B, Corticoamygdala coupling as a marker of early relapse risk in cocaine-addicted individuals. Front Psychiatry. 2014; 5. https://doi.org/10.3389/fpsyt.2014.00016.
57. McHugh MJ, Gu H, Yang Y, Adinoff B, Stein EA. Executive control network connectivity strength protects against relapse to cocaine use. Addict Biol. 2017;22:1790-801.

58. Motzkin JC, Baskin-Sommers A, Newman JP, Kiehl KA, Koenigs M. Neural correlates of substance abuse: reduced functional connectivity between areas underlying reward and cognitive control. Hum Brain Mapp. 2014;35:4282-92.

59. Verdejo-Garcia A, Contreras-Rodríguez O, Fonseca F, Cuenca A, Soriano-Mas C, Rodriguez J, et al. Functional alteration in frontolimbic systems relevant to moral judgment in cocaine-dependent subjects. Addict Biol. 2014;19:272-81.

60. Zhang S, Li CSR Ventral striatal dysfunction in cocaine dependence-difference mapping for subregional resting state functional connectivity. Transl Psychiatry. 2018; 8. https://doi.org/10.1038/s41398-018-0164-0.

61. Kohno M, Morales AM, Ghahremani DG, Hellemann G, London ED. Risky decision making, prefrontal cortex, and mesocorticolimbic functional connectivity in methamphetamine dependence. JAMA Psychiatry. 2014;71:812-20.

62. Kohno M, Okita K, Morales AM, Robertson CL, Dean AC, Ghahremani DG, et al. Midbrain functional connectivity and ventral striatal dopamine D2-type receptors: link to impulsivity in methamphetamine users. Mol Psychiatry. 2016;21:1554-60.

63. Kohno M, Loftis JM, Huckans M, Dennis LE, McCready H, Hoffman WF. The relationship between interleukin- 6 and functional connectivity in methamphetamine users. Neurosci Lett. 2018;677:49-54.

64. Li X, Su H, Zhong N, Chen T, Du J, Xiao K, et al. Aberrant resting-state cerebellarcerebral functional connectivity in methamphetamine-dependent individuals after six months abstinence. Front Psychiatry. 2020;11:191.

65. Wang Y, Yan KJ, Fan CX, Luo XN, Zhou Y. Altered functional connectivity of the nucleus accumbens subdivisions in amphetamine-type stimulant abusers: a resting-state fMRI study. BMC Neurosci. 2019;20:66.

66. Ding W-N, Sun JH, Sun YW, Zhou Y, Li L, Xu JR, et al. Altered default network resting-state functional connectivity in adolescents with internet gaming addiction. PLoS ONE. 2013; 8. https://doi.org/10.1371/journal.pone.0059902.

67. Xiaonian W, Fenjuan L, Xianghe Q, Wenbin Y, Jie L, Chunjie L. Single-photon emission computed tomography for the diagnosis of mandibular invasion caused by oral cancers: a systematic review and meta-analysis. Hua Xi Kou Qiang Yi Xue Za Zhi. 2017;35:413-8.

68. Wang L, Zou F, Zhai T, Lei $Y$, Tan S, Jin X, et al. Abnormal gray matter volume and resting-state functional connectivity in former heroin-dependent individuals abstinent for multiple years. Addict Biol. 2016;21:646-56.

69. Zhai TY, Shao YC, Xie CM, Ye EM, Zou F, Fu LP, et al. Altered intrinsic hippocmapus declarative memory network and its association with impulsivity in abstinent heroin dependent subjects. Behav Brain Res. 2014;272:209-17.

70. Zhang Y, Gong J, Xie C, Ye EM, Jin X, Song H, et al. Alterations in brain connectivity in three sub-regions of the anterior cingulate cortex in heroindependent individuals: evidence from resting state fMRI. Neuroscience. 2015;284:998-1010.

71. Zou F, Wu X, Zhai T, Lei $Y$, Shao $Y$, Jin $X$, et al. Abnormal resting-state functional connectivity of the nucleus accumbens in multi-year abstinent heroin addicts. J Neurosci Res. 2015;93:1693-702.

72. Contreras-Rodríguez O, Albein-Urios N, Perales JC, Martínez-Gonzalez JM, VilarLópez R, Fernández-Serrano MJ, et al. Cocaine-specific neuroplasticity in the ventral striatum network is linked to delay discounting and drug relapse. Addiction. 2015;110:1953-62.

73. Jung $M H$, Kim JH, Shin YC, Jung WH, Jang JH, Choi JS, et al. Decreased connectivity of the default mode network in pathological gambling: a resting state functional MRI study. Neurosci Lett. 2014;583:120-5.

74. Koehler S, Ovadia-Caro S, van der Meer E, Villringer A, Heinz A, RomanczukSeiferth $\mathrm{N}$, et al. Increased functional connectivity between prefrontal cortex and reward system in pathological gambling. PLoS One. 2013;8:e84565.

75. Chen $\mathrm{CY}$, Yen JY, Wang PW, Liu GC, Yen CF, Ko CH. Altered functional connectivity of the insula and nucleus accumbens in internet gaming disorder: a resting state fMRI study. Eur Addict Res. 2016;22:192-200.

76. Chen X, Wang Y, Zhou Y, Sun Y, Ding W, Zhuang Z et al., Different resting-state functional connectivity alterations in smokers and nonsmokers with internet gaming addiction. 2014. https://doi.org/10.1155/2014/825787.

77. Hong SB, Harrison BJ, Dandash O, Choi EJ, Kim SC, Kim HH, et al. A selective involvement of putamen functional connectivity in youth with internet gaming disorder. Brain Res. 2015;1602:85-95.

78. Lin F, Zhou Y, Du Y, Zhao Z, Qin L, Xu J, et al. Aberrant corticostriatal functional circuits in adolescents with internet addiction disorder. Front Hum Neurosci. 2015;9:356.

79. Yuan K, Yu D, Cai C, Feng D, Li Y, Bi Y, et al. Frontostriatal circuits, resting state functional connectivity and cognitive control in internet gaming disorder. Addict Biol. 2017;22:813-22.

80. Zhang JT, Ma SS, Yip SW, Wang LJ, Chen C, Yan CG, et al. Decreased functional connectivity between ventral tegmental area and nucleus accumbens in 
Internet gaming disorder: evidence from resting state functional magnetic resonance imaging. Behav Brain Funct. 2015; 11. https://doi.org/10.1186/ s12993-015-0082-8.

81. Zhang JT, Yao YW, Li CSR, Zang YF, Shen ZJ, Liu L, et al. Altered resting-state functional connectivity of the insula in young adults with Internet gaming disorder. Addict Biol. 2016;21:743-51.

82. Suckling J, Nestor LJ. The neurobiology of addiction: the perspective from magnetic resonance imaging present and future. Addiction. 2017;112:360-9.

83. Zilverstand A, O'Halloran R, Goldstein RZ Resting-state and structural brain connectivity in individuals with stimulant addiction. In: The Routledge handbook of philosophy and science of addiction. Routledge: 1 [edition]. | New York: Routledge, 2018. | Series: Routledge handbooks in philosophy, 2019, pp 362-79.

84. Tolomeo S, Gray S, Matthews K, Steele JD, Baldacchino A. Multifaceted impairments in impulsivity and brain structural abnormalities in opioid dependence and abstinence. Psychol Med. 2016;46:2841-53.

85. Groman SM, Morales AM, Lee B, London ED, Jentsch JD. Methamphetamineinduced increases in putamen gray matter associate with inhibitory control. Psychopharmacology. 2013;229:527-38.

86. Bahk JY, Li S, Park MS, Kim MO. Dopamine D1 and D2 receptor mRNA upregulation in the caudate-putamen and nucleus accumbens of rat brains by smoking. Prog Neuro-Psychopharmacol Biol Psychiatry. 2002;26:1095-104.

87. Gradin VB, Baldacchino A, Balfour D, Matthews K, Steele JD. Abnormal brain activity during a reward and loss task in opiate-dependent patients receiving methadone maintenance therapy. Neuropsychopharmacology. 2014;39:885-94.

88. Schlagenhauf F, Rapp MA, Huys QJ, Beck A, Wustenberg T, Deserno $L$, et al. Ventral striatal prediction error signaling is associated with dopamine synthesis capacity and fluid intelligence. Hum Brain Mapp. 2013;34:1490-9.

89. Shackman AJ, Salomons TV, Slagter HA, Fox AS, Winter JJ, Davidson RJ. The integration of negative affect, pain and cognitive control in the cingulate cortex. Nat Rev Neurosci. 2011;12:154-67.

90. Tolomeo S, Christmas D, Jentzsch I, Johnston B, Sprengelmeyer R, Matthews K et al. A causal role for the anterior mid-cingulate cortex in negative affect and cognitive control. Brain. 2016;139:1844-54.

91. Volkow ND, Wang GJ, Fowler JS, Logan J, Gatley SJ, Gifford A, et al. Prediction of reinforcing responses to psychostimulants in humans by brain dopamine D2 receptor levels. Am J Psychiatry. 1999;156:1440-3.

92. Volkow ND, Fowler JS, Wang GJ. Role of dopamine in drug reinforcement and addiction in humans: results from imaging studies. Behav Pharm. 2002;13:355-66.

93. Volkow ND, Fowler JS, Wang GJ, Baler R, Telang F. Imaging dopamine's role in drug abuse and addiction. Neuropharmacology. 2009;56:3-8.

94. Zeater N, Buzás P, Dreher B, Grünert U, Martin PR. Projections of three subcortical visual centers to marmoset lateral geniculate nucleus. J Comp Neurol. 2019;527:535-45.

95. Yu R, Zhao L, Tian J, Qin W, Wang W, Yuan K, et al. Regional homogeneity changes in heavy male smokers: a resting-state functional magnetic resonance imaging study. Addict Biol. 2013;18:729-31.

96. Wang XF, Xue T, Dong F, Li YD, Xie DD, Liu C, et al. The changes of brain functional networks in young adult smokers based on independent component analysis. Brain Imaging Behav. 2021;15:788-97.

97. Camchong J, Stenger VA, Fein G. Resting state synchrony in long-term abstinent alcoholics with versus without comorbid drug dependence. Drug Alcohol Depend. 2013;131:56-65.

98. Halcomb ME, Chumin EJ, Goñi J, Dzemidzic M, Yoder KK. Aberrations of anterior insular cortex functional connectivity in nontreatment-seeking alcoholics. Psychiatry Res-Neuroimaging. 2019;284:21-28.

99. Müller-Oehring E, Jung Y, AP-C, 2015 undefined. The resting brain of alcoholics. academic.oup.com https://academic.oup.com/cercor/article-abstract/25/11/ 4155/2366345 (Accessed 29 May 2020).

100. Harrison PJ. The neuropathology of schizophrenia-A critical review of the data and their interpretation. Brain. 1999;122:593-624.

101. Wang J, Fan Y, Dong Y, Ma M, Ma Y, Dong Y, et al. Alterations in brain structure and functional connectivity in alcohol dependent patients and possible association with impulsivity. PLoS ONE. 2016; 11. https://doi.org/10.1371/journal. pone.0161956.

102. Wang J, Fan $Y$, Dong $Y$, Ma M, Dong $Y$, Niu $Y$, et al. Combining gray matter volume in the cuneus and the cuneus-prefrontal connectivity may predict early relapse in abstinent alcohol-dependent patients. PLoS ONE. 2018; 13. https:// doi.org/10.1371/journal.pone.0196860.

103. Weiland BJ, Sabbineni A, Calhoun VD, Welsh RC, Bryan AD, Jung RE, et al. Reduced left executive control network functional connectivity is associated with alcohol use disorders. Alcohol Clin Exp Res. 2014;38:2445-53.

104. Li Q, Yang WC, Wang YR, Huang YF, Li W, Zhu J, et al. Abnormal function of the posterior cingulate cortex in heroin addicted users during resting-state and drug-cue stimulation task. Chin Med J. 2013;126:734-9.

105. Lin HC, Wang PW, Wu HC, Ko CH, Yang YH, Yen CF. Altered gray matter volume and disrupted functional connectivity of dorsolateral prefrontal cortex in men with heroin dependence. Psychiatry Clin Neurosci. 2018;72:435-44.

106. Zhou S, Xiao D, Peng P, Wang S-K, Liu Z, Qin H-Y, et al. Effect of smoking on resting-state functional connectivity in smokers: an fMRI study. Respirology. 2017;22:1118-24.

107. Liu T, Li J, Zhao Z, Zhong Y, Zhang Z, Xu Q, et al. Betel quid dependence is associated with functional connectivity changes of the anterior cingulate cortex: a resting-state fMRI study. J Transl Med. 2016;14:1-13.

\section{ACKNOWLEDGEMENTS}

This work was supported by Tier 2 Start Up Grant RC-OFSGT2/20-21/BUS/003. The funders had no role in study design, data collection, analysis, and interpretation of the data; preparation, review, or approval of the manuscript; and decision to submit the manuscript for publication.

\section{AUTHOR CONTRIBUTIONS}

ST: conceptualization, methodology, formal analysis, investigation, writing original draft. RY: conceptualization. methodology, writing- review \& editing.

\section{COMPETING INTERESTS}

The authors declare no competing interests.

\section{ADDITIONAL INFORMATION}

Supplementary information The online version contains supplementary material available at https://doi.org/10.1038/s41398-022-01792-6.

Correspondence and requests for materials should be addressed to Serenella Tolomeo or Rongjun Yu.

Reprints and permission information is available at http://www.nature.com/ reprints

Publisher's note Springer Nature remains neutral with regard to jurisdictional claims in published maps and institutional affiliations.

Attribution 4.0 International License, which permits use, sharing, adaptation, distribution and reproduction in any medium or format, as long as you give appropriate credit to the original author(s) and the source, provide a link to the Creative Commons license, and indicate if changes were made. The images or other third party material in this article are included in the article's Creative Commons license, unless indicated otherwise in a credit line to the material. If material is not included in the article's Creative Commons license and your intended use is not permitted by statutory regulation or exceeds the permitted use, you will need to obtain permission directly from the copyright holder. To view a copy of this license, visit http://creativecommons. org/licenses/by/4.0/.

(c) The Author(s) 2022 